\title{
LOS DERECHOS PARTICIPATIVOS: ¿INSTRUMENTOS AL SERVICIO DE LA REPRESENTACIÓN O DERECHOS AUTÓNOMOS?*
}

\author{
Francisco Marín Martínez \\ Abogado y Doctor en Derecho por la Universidad de Valencia
}

\section{ABSTRACT}

Resumen: Los derechos participativos de los trabajadores y trabajadoras encuentran su regulación principalmente a nivel nacional en nuestro artículo 64 ET. El concepto global de "participación" engloba hoy en día la información pasiva, la consulta y la participación, entendida ahora como concepto activo con base en el cual los trabajadores y trabajadoras ejercen determinado poder de decisión en la empresa. No obstante, uno de los aspectos clave a la hora de determinar la naturaleza de este tipo de derechos es si estos son autónomos y por consiguiente dependientes de si mismos, o si son por el contrario tan sólo instrumentales de las instancias representativas de los trabajadores y trabajadoras en la empresa. La respuesta a esta duda esclarecerá determinadas dudas cruciales a la hora de comprender el alcance de este tipo de derechos.

Palabras clave: información, consulta, participación, instrumental, autónomo.

* Este artículo forma parte de la Tesis Doctoral del autor Los derechos de información, consulta y participación, defendida en 2015 en la Facultad de Dret de la Universitat de València, presentado como Comunicación en el II Encuentro de Profesionales del Asesoramiento Laboral y Social, celebrado en la Facultad de Relaciones Laborales y Trabajo Social (UPV/EHU-Leioa) el día 30 de septiembre de 2016. 
Abstract: Participatory rights of workers are mainly regulated at the national level in our article 64 ET. The overall concept of "participation" currently includes passive information, consultation and participation now understood as an active concept under which workers exercise certain decision-making power in the company. However, one of the key issues when determining the nature of such rights is whether they are autonomous and dependent of themselves, or whether they are, on the contrary, only instruments for the representation of workers in the company. The answer to this question will clarify certain crucial questions in terms of understanding the scope of such rights.

Keywords: information, consultation, participation, instrumental, autonomous. 


\section{SUMARIO}

Sumario: 1. El entendimiento como derechos instrumentales. 2. El carácter de los derechos autónomos. 3. La instrumentalidad interna de los derechos participativos. 4. Bibliografía.

\section{El entendimiento como derechos instrumentales}

Una posible interpretación acerca de la naturaleza de los derechos de información, consulta y participación de los trabajadores es la de considerarlos como derechos instrumentales al servicio de la función representativa. Se pretendería pues, defender una tesis según la cual, sin representación de los trabajadores institucionalizada o legalizada, estos derechos no tendrían razón de ser. CASAS ha afirmado que los derechos de información vienen contemplados en el ET como situación jurídica instrumental, medial o preparatoria al ejercicio de la acción representativa del Comité de Empresa y de los Delegados de Personal, medios que le permiten desarrollar efectivamente sus funciones en los lugares de trabajo y cumplir con su cometido institucional. La lectura del precepto permite, pues, llegar a la conclusión de que la titularidad de esos derechos se reserva por ley sólo a esos Delegados de Personal y Comités de Empresa (Rodríguez-Piñero, 1990: 57).

La función de los representantes de los trabajadores vendría a marcar el alcance y límites de estos derechos sin que cupiera una normativa que se desmarcara de ésta. En la historia, el movimiento obrero, desarrolló dos vertientes reivindicativas que se pueden definir como la de lo urgente (condiciones de vida inmediatas de la clase trabajadora) y la de lo importante (sistema político-económico que priva a la clase trabajadora de los medios de producción) - lo cual no significa que lo urgente carezca de importancia, sino más bien que se limita al corto plazo, al día a día, sin entrar a trastocar la estructura sobre la que descansa el modo de producción y reparto de la propiedad y beneficios empresariales-. Pues bien, los sindicatos que ostentan la representación de los trabajadores se decantaron, - al menos mayormente- con el tiempo, hacia la reivindicación de lo urgente. Esto ha sido definido como la lucha económica, en contraposición a la lucha política, desarrollada más bien por los partidos políticos obreros ${ }^{1}$.

1 En este sentido Harnecker (1902: 23-24) ha desarrollado estos conceptos propios de Lenin, V. I. (1902: 168). 
La consideración de los derechos de información, consulta y participación como derechos instrumentales de la función representativa recoge esta evolución histórica, esta voluntad de centrarse en las reivindicaciones que atañen al día a día del trabajador en la empresa y consecuentemente ven su ámbito de aplicación limitado a aquellos asuntos que afecten a cuestiones directamente relacionadas con el empleo tales como: cuantía salarial, tipos y modalidades de contratos de trabajo utilizados en la empresa, accidentes laborales, enfermedades profesionales o sanciones a los trabajadores, entre otros. También se reconocen hoy en día derechos de este tipo en cuanto a cuestiones no directamente relacionadas con el empleo, como el conocimiento de documentos contables tales como el balance o la cuenta de resultados de la empresa, pero que en última instancia responden a la necesidad de los representantes de conocer ciertos datos de carácter económico con el fin de poder negociar o ser consultados con cierto criterio acerca de las condiciones de trabajo anteriormente expuestas. En definitiva, la información que se proporciona en estos casos está indirectamente relacionada con el empleo ya que es utilizada como medio con el fin de desarrollar la labor representativa para la defensa de «lo urgente».

En este sentido, de la misma forma que el contenido de estos derechos no podría ir más allá de lo necesario para ejercer la función representativa, tampoco podrían estos derechos encontrar límites que no permitieran a los representantes desarrollar su labor en condiciones de normalidad. Esta labor, todo sea dicho, no es otra que la de proteger y hacer valer los intereses de los trabajadores mediante los instrumentos legalmente establecidos para ello. A su vez, los derechos de información, consulta y participación serían medios para poder llevar a cabo la labor representativa, como por ejemplo una negociación de un convenio colectivo que defina ciertos aspectos laborales en una empresa.

Según esta tesis son los representantes los titulares de estos derechos, no teniendo sentido otorgar capacidad informativa, ni mucho menos consultiva o participativa a los trabajadores que carecen de representantes en las empresas donde prestan sus servicios, creando así una desigualdad notoria entre unos trabajadores y otros. También supondría la incapacidad de los trabajadores de exigir a sus representantes el buen ejercicio de tales derechos ya que los trabajadores no serían titulares de estos, siendo la única forma de contestación a una mala gestión el castigo electoral en las elecciones a representantes de los trabajadores en las empresas o incluso la no sindicación en uno u otro sindicato. Nos situamos de esta forma en el plano de un mandato de carácter representativo.

En esta línea la naturaleza jurídica de estos derechos de información, consulta y participación, habría de ser la de potestad jurídica, ya que la titularidad del derecho es otorgada a los representantes pero para la defensa de un interés ajeno —el de los trabajadores—, lo cual imposibilitaría definirlos como dere- 
chos subjetivos ya que estos se caracterizan por ser poderes de actuación para la satisfacción de unos intereses propios. El ejercicio de estas potestades se traduce en situaciones de derecho-deber en las cuales el titular ha de actuar cuando sea legal o convencionalmente establecido, no estando simplemente determinado por la voluntad de este (Garrido, 1995: 71 y ss.).

Por otro lado, otorgar la titularidad de estos derechos a los representantes posibilitaría su integración como parte de la libertad sindical, con su consiguiente protección constitucional —al menos en el ordenamiento español— del artículo 28.1 CE o incluso del artículo $37 \mathrm{CE}$ en tanto que para poder llevar a cabo una negociación colectiva en condiciones de igualdad la parte sindical ha de estar bien informada sobre ciertas cuestiones. Es decir, que los derechos de información, consulta y participación podrían formar parte del derecho a la libertad sindical en su vertiente colectiva, esto es, referida al conjunto de derechos y facultades que corresponden al sindicato como sujeto colectivo. Una faceta de esta libertad sindical colectiva es el libre ejercicio de la actividad sindical, en la empresa o fuera de ella, y que se resuelve en una serie de medios de acción, muchos de ellos regulados como derechos de manera separada a la libertad sindical (Baylos, 2009: 22). Sin embargo, y como será ampliado en el tercer apartado de este trabajo, el TC ha venido a construir una teoría restrictiva según la cual la libertad es otorgada tan sólo a los sindicatos como tales pero no a las instancias de representación unitaria de los trabajadores que de hecho ejercer labores de naturaleza sindical.

Otro problema que surge con la calificación jurídica de estos derechos no es otro que el de la transmisión de la información recibida por los representantes a los trabajadores representados. Tampoco encuentra razón de ser esta transmisión desde el momento en que los representantes, al haber tenido acceso a esta información, pueden desarrollar su labor sin necesidad de transmitirla a los trabajadores. A través de la función mediadora participativa se canaliza hacia los trabajadores tan sólo una parte de la información que el órgano puede recibir, siendo por lo demás su determinación cualitativa y cuantitativa ajena a los trabajadores (Garrido, 1995: 75). De la misma forma, tampoco sería necesario que los representantes consultasen con sus representados antes de ser ellos mismos consultados mediante un informe o en un periodo de consultas; y por último lo mismo ocurriría en el caso de que existieran mecanismos de participación en la empresa.

Los distintos ordenamientos jurídicos incluyen la necesidad de que la información recibida por parte de los representantes sea transmitida a los trabajadores, pero también existe en todos los casos una figura que niega o al menos limita la anterior, como puede ser un deber de sigilo que, obviamente, limita esta misma transmisión de la información. En este momento no es preciso entrar en detalles acerca de estas distintas figuras ni acerca de su alcance y límites, sin em- 
bargo sí es necesario denotar que esta contradicción existe y que, según la tesis que se viene exponiendo, sería el sigilo quien determinase hasta qué punto la información puede o debe ser transmitida y no viceversa. Se trata de una visión limitadora de los derechos de información, consulta y participación que exigiría cada vez la prueba de que es necesario informar, consultar o participar para que la labor representativa pudiera llevarse a cabo.

Estas consideraciones llevan directamente a plantearse cuál es la naturaleza de la representación de los trabajadores y si una vez elegidos como tales, los representantes son libres de actuar como crean conveniente - siempre dentro del respeto a la buena fe y a los fines de la propia representación-, o si, por el contrario, se trata de una representación cuya mera razón de ser es la de facilitar el diálogo y el contacto entre trabajadores y empresario, es decir, un mero interlocutor sumiso a los dictados de sus representados.

En definitiva, definir la representación de los trabajadores como un mandato representativo, esto es, otorgando libertad de actuación a los representantes una vez estos han sido elegidos, podría desembocar en que los derechos de información, consulta y participación fueran considerados instrumentos de dicha representación y ostentados, por consiguiente, por dichos representantes. Ámbito material limitado a temática de empleo, deber de sigilo con mayor cobertura legal y negación de estos derechos a los trabajadores que no cuentan con representación en sus centros de trabajo son algunas de las consecuencias de esta consideración.

Sin embargo, cabe la posibilidad de optar por la opción de que la representación de los trabajadores se configure como un mandato imperativo, esto es, que exija que el representante actúe como mera correa de transmisión necesitando por tanto estar en mayor contacto con sus representados. Se apoyaría, de esta forma, la tesis según la cual estos derechos son autónomos de la función representativa y que, consecuentemente, los sujetos titulares de los mismos sean los propios trabajadores, como veremos a continuación.

\section{El carácter de derechos autónomos}

Considerar a los representantes de los trabajadores como meros interlocutores entre las partes implicadas - trabajadores y empresario- simplemente trasladando la opinión y defendiendo los intereses de los primeros, llevaría directamente a considerar los derechos de información, consulta y participación, como derechos autónomos, propios de los trabajadores, y distintos de la mera labor representativa, pasando a ser ella misma instrumento para el ejercicio de los derechos de información, consulta y participación y no viceversa. El carácter eminentemente interno de una información circunscrita al funcionamiento y de- 
sarrollo de una concreta empresa como actividad económica y organizativa, es la que inicialmente daría origen a la constatación de un interés privado, el que poseen los elementos personales de dicha actividad a tener conocimiento de determinados datos sobre la misma (Garrido, 1995: 67). Esta posibilidad vendría dada según un análisis literal del artículo $4 \mathrm{~g}$ ) ET al disponer éste que los trabajadores tienen como derechos básicos, con el contenido y alcance que para cada uno de los mismos disponga su específica normativa, los de: información, consulta y participación en la empresa. En consecuencia, aunque el contenido y el alcance pueda ser delimitado o limitado por una específica normativa, los sujetos de derechos son los trabajadores. Delimitar el alcance y contenido de un derecho no puede suponer una modificación de su naturaleza ni del sujeto de derecho, así, y siempre según la literalidad del artículo 4 g) ET, los derechos de información, consulta y participación en la empresa serían derechos autónomos de los trabajadores, y la función de los representantes no sería más que la de hacerlos valer y ejecutarlos.

Esta tesis encuentra su fundamento en la consideración de los trabajadores como parte integrante de la empresa, a la postre como personas de la propia empresa y no como meras partes materiales con un coste económico para ésta. Se trata de otorgarles unos derechos a ellos mismos por el «mero» hecho de ser quienes con su trabajo dan vida a la propia actividad empresarial. Estos derechos irían más allá de la entrega de un salario como contraprestación y de la existencia de unos límites de explotación encaminados a aliviar o limitar ciertas condiciones penosas o peligrosas en el desarrollo de la prestación laboral.

Se trataría pues de derechos anteriores a la existencia de la propia representación de los trabajadores, derechos propios de estos trabajadores para los cuales en ocasiones es necesario o simplemente proporciona una mayor funcionalidad la existencia de representantes de los trabajadores en la empresa. Toda vez que, si no existiera tal figura - la del representante - no dejaría de existir un deber legal del empresario de proporcionar cierta información o de consultar a los propios trabajadores e incluso de hacerlos participar mediante algún mecanismo en los asuntos empresariales que correspondiera.

Sería también conveniente un reconocimiento, no solamente legal de esta titularidad de los derechos por parte de los trabajadores y de sus consecuencias aplicativas, sino también un reconocimiento de carácter constitucional. Una cobertura que reconociera la existencia de estos derechos explícitamente, o como poco a consecuencia de la elevación de la condición del trabajador. Una definición del trabajo que implicara que quien lo desempeńa es algo más que un elemento del engranaje empresarial. Ejemplo de ello es el artículo 1 de la Constitución de la II República española de 1931, según el cual «España es una República democrática de trabajadores de toda clase, que se organiza en régimen de Libertad $y$ de Justicia». Una definición de estas características es muy recomendable sin 
duda, sin embargo y como vengo diciendo, el reconocimiento constitucional de estos derechos debería ser explícito evitando la posibilidad de que se recurriera a interpretaciones posteriores de un precepto genérico como el artículo 1 de la Constitución republicana, que pudieran llevar a la conclusión de que no basta tal definición para concluir que los trabajadores han sido en lo concreto provistos de unos derechos tales como los de información, consulta o participación en el seno de sus empresas.

En mi opinión, si bien una definición de este tipo no explicita la existencia de estos derechos, sí en cambio, sería premisa suficiente para desarrollar un sistema de relaciones laborales que elevara al trabajador a un nivel superior con capacidad participativa en el seno de las empresas. Sistema que debería sin lugar a dudas recoger la existencia de derechos de información, consulta y participación cuyos titulares serían los trabajadores. De esta forma, el artículo 46 de la Constitución de 1931 configura el trabajo como «obligación social» y estipula que la legislación social de la República regulará, entre otras cosas, "la participación de los obreros en la dirección, la administración y los beneficios de las empresas, y todo cuanto afecte a la defensa de los trabajadoresn. Encontramos una posible referencia de esta naturaleza en el artículo 129.2 de la Constitución Española de 1978, al disponer este artículo que «los poderes públicos promoverán eficazmente las diversas formas de participación en la empresa...». Sin embargo, ni se trata de un derecho — i mucho menos de un derecho fundamental—, sino más bien de un mandato a los poderes públicos; ni se refiere a los trabajadores como posibles titulares de un ulterior derecho en el caso de que los poderes públicos desarrollaran este precepto, cosa que si hizo la Constitución republicana. En definitiva, en modo alguno la Constitución Española pone al trabajador en el plano que viene definiéndose.

Se estaría reconociendo a los trabajadores como titulares de estos derechos, no simplemente por razones de conservación o mejora de condiciones laborales, sino con un fundamento teleológico encaminado a elevar al trabajador a una posición activa en la empresa, a una posición que, pese a no entrar en el terreno de la propiedad, se acercaría al menos a unas potestades de gestión mucho más importantes que de las que gozan hoy en día.

Si esta tesis es aceptada, el contenido de los derechos de información, los temas y situaciones sobre las cuales los trabajadores - $\mathrm{O}$ sus representantes- habrían de ser consultados y sobre los mecanismos de participación habrían de ver su contenido material ampliado. Y esto es así ya que no se trata de dar información o consultar acerca solamente de cuestiones de empleo sino que como parte de la empresa los trabajadores podrían exigir, o el legislador debería concederles, derechos de información sobre otros temas como por ejemplo aquellos relativos a la contaminación que produce la empresa, los clientes con la que ésta trata y el respeto de estos por las normas internacionales, o incluso crear mecanismos de 
participación, ya no sólo en la gestión, sino también mediante el reparto de beneficios entre los propios trabajadores.

Las consecuencias se revierten en todos los aspectos que han sido analizados con anterioridad en cuanto al carácter instrumental de estos derechos. No está de más recalcar que en ningún momento se está negando la existencia o la idoneidad de una representación de los trabajadores en la empresa. Ésta es muchas veces necesaria incluso en más casos de los que hoy en día son reconocidos. Simplemente, la función representativa es un instrumento para que los propios trabajadores vean ejercido su derecho por sus representantes. Pero estos derechos no se detendrían en el punto de los derechos reconocidos a los representantes, al ser autónomos y previos a la propia representación, sino que podrían ir más allá. Esto quedaría patente tanto en los casos en que, pese a existir representación, los derechos expresamente otorgados a los representantes no abarcasen todo el contenido de los derechos de información, consulta y participación, y también, por supuesto, en los casos en los que directamente los trabajadores de un centro o empresa carecieran de toda figura representativa de sus intereses y tuvieran que ser ellos mismos quienes de primera mano ejercieran sus derechos.

Los representantes de los trabajadores, en el caso de que los hubiera, llevarían a cabo un mandato imperativo, ligados a los dictados de sus representados y obligados a rendir cuentas a estos. En la práctica esto implicaría ya no sólo el derecho de los representantes a informar a sus representados acerca de aquello sobre lo que han sido informados o consultados, sino el deber de estos de informar a los trabajadores e incluso a consultar con ellos antes incluso de llevar a cabo su labor. Lo que podría suponer un problema de aplicabilidad de los derechos y de ralentización de la vida empresarial con lo cual no podría tampoco llevarse al límite esta apreciación, manteniendo unos límites de independencia de actuación de los representantes que no impidieran que estos ejercieran su función encaminada a defender los intereses de los trabajadores en el seno de las empresas o centros de trabajo. Por otra parte, el intento de aplicación de mecanismos participativos de estas características ha encontrado en los mismos sindicatos un opositor, ya que debido al celo por mantener su posición dentro del sistema industrial, los dirigentes sindicales a menudo acogieron con recelo muchas de las ideas más ambiciosas de control total por parte de los trabajadores. Así pues, los dirigentes de las organizaciones de trabajadores consolidadas están interesados en asegurar que la participación de los trabajadores esté claramente integrada en la estructura sindical establecida (Poole, 1995: 159).

En mi opinión se trata de un error confrontar esta tesis con la importancia del fenómeno sindical y de la representación de los trabajadores. No hay que olvidar la función histórica del asociacionismo obrero, que es una mejor instrumentalización y canalización de los intereses de clase. Es decir, si los derechos de información, consulta y participación son titularidad de los trabajadores y, 
consecuentemente, pueden hacerlos valer en todo caso, se estaría fomentando la creación de sindicatos allá donde ahora no los hay precisamente para una mejor instrumentalización de estos nuevos derechos. Existiría, pues, una demanda social en pro de crear estructuras representativas en las numerosísimas empresas y centros carentes de ellas.

En cuanto al deber de sigilo o figuras similares que se vienen imponiendo a los representantes de los trabajadores, cabría concluir que éstas no tendrían sentido entre los representantes y sus representados por todo lo que se viene explicando. Consecuentemente, se habría de llegar también a la conclusión de que es necesaria una especie de "inversión de la carga de la prueba» en cuanto a la transmisión de información entre representantes y representados, debiéndose probar por parte del empresario, en este caso, el perjuicio que para la empresa supondría llevar a cabo tal transmisión de información, o tal consulta o participación, existiendo en cambio, una presunción iuris tantum acerca de la idoneidad de estos derechos cuyos titulares son el conjunto de los trabajadores.

En cambio, sí deberían seguir existiendo estos límites a la transmisión de la información entre los representantes y terceras personas y por supuesto deberían también existir entre los propios trabajadores - que recibieran ciertas informaciones de primera mano o mediante sus representantes- y terceras personas ajenas a la empresa ya que éstas no forman parte de la vida empresarial y son por lo tanto ajenas a dichas informaciones.

La información, consulta y participación se configuran pues, no solamente como derechos subjetivos de los trabajadores, sino también como deberes. Deberes de los representantes de los trabajadores consistentes en ejercer su labor con diligencia ya que están ejercitando un derecho que no les pertenece de primera mano; pero también deberes de los propios trabajadores a los cuales se les han otorgado unos derechos que los ubican en un estadio más alto dentro de las estructuras empresariales y que, han de ir aparejados a una mayor responsabilidad, a unos deberes genéricos también de diligencia y buena fe en el trato y ejercicio de esta información, consulta o participación. Pero también se derivan de ello unos deberes concretos como el de sigilo, que si bien es una figura que se aplica a los representantes de los trabajadores, en este caso se aplicaría a los propios trabajadores como titulares de estos derechos. De esta forma, los trabajadores, como tales, deberían implicarse y conocer las informaciones a las que tienen acceso, igualmente deberían realizar los informes pertinentes, ya no porque tuvieran derecho a hacerlo, sino porque se trataría de su deber como parte activa en la empresa y en su funcionamiento. Podrían incluso entenderse estos derechos como un deber jurídico, concretamente como una carga, entendida esta como «un comportamiento al cual el sujeto está constreńido para realizar un interés propio; es decir, una necesidad para realizar un derecho suyo (Blasco, 2003: 295). 
Pero establecer estos deberes y este tipo de responsabilidades cuando la propiedad empresarial no les pertenece corre el riesgo de caer en concepciones corporativistas que falsean la real contradicción capital-trabajo imperante en el sistema capitalista. Los derechos participativos autónomos pueden entenderse, pues, en un contexto democrático en la empresa, es decir, cuando este presenta el modo cooperativo real - sin figuras como la del socio capitalista- o cuando se trata de una empresa de titularidad pública.

Lo que no ocurre en ningún caso es que pueda llamarse democrático un modelo en el cual empresa sea sinónimo de capital repartido en acciones, participaciones, etc. cuya propiedad se adquiera por diversos medios ajenos al trabajo (desembolso de capital, herencia, etc.), y los trabajadores sean «sujetos» ajenos a todo ello desempeñando un rol meramente productivo. De hecho, se ha descrito el objeto del consenso político y jurídico del constitucionalismo de posguerra como un intercambio entre seguridad material de las clases trabajadoras y renuncia a la democratización radical de la vida política y económica (Baylos, 2013: 25).

Estas consideraciones llevan directamente a plantearse las consecuencias que acarrearía en el conjunto de la legislación laboral una real implantación de los derechos participativos. O más bien habría que plantearse la puesta en marcha de distintas condiciones previas esenciales para que esta implantación fuera real y adecuada. Al estar trastocando de raíz la figura del trabajador como tal, dicha legislación debería amoldarse a esta figura. El ordenamiento jurídico -laboral en este caso- ha de ser coherente en su conjunto, evitando contradicciones conceptuales y aplicativas. De esta forma, si se pasa a considerar al trabajador como algo más que un simple elemento cuasi-deshumanizado que presta un servicio dentro de unos límites legales de salario, higiene, seguridad, etc., para considerarlo parte activa en la empresa como una especie de "ciudadano" dentro de la misma, el régimen de contratación y despido debería verse consecuentemente afectado. No son aceptables dentro de este esquema figuras como, por ejemplo, el despido improcedente o los abusos - legislativos y aplicativos - en la contratación temporal que en definitiva desvinculan al trabajador de la empresa, que es vista por éste como un lugar de paso y no de desarrollo de su capacidad productiva a largo plazo, elemento que en definitiva es el que otorga al trabajador el estatus al que vengo refiriéndome.

Por supuesto, la aplicación de esta tesis pasa en última instancia por trastocar el esquema de propiedad de las empresas puesto que si tal derecho es detentando por persona distinta a los trabajadores/ciudadanos tan sólo puede aspirarse a sistemas de "participación" parcial y prácticamente caritativa y de supervivencia como los existentes en España o los países de su entorno. Y este cambio de sistema nunca vendrá determinado por el propio derecho, puesto que éste no es sino un elemento superestructural (según Marx) o estructural (según 
Harris), es decir que no marca las relaciones de producción sino que es reflejo de ellas, de modo que serán éstas y la correlación real de fuerzas en la contradicción capital/trabajo (estructura Marxiana o infraestructural Harrisiana) la que llevará a un cambio de facto que creará consecuentemente un derecho emancipador de clase. En este sentido y en palabras de ROMAGNOLI «El derecho del trabajo tiene derecho a hablar pero siempre que no alce demasiado la voz, sin que pueda presentarse como un mecanismo de emancipación».

\section{La instrumentalidad interna de los derechos participativos}

Cuestión distinta es la de advertir que los derechos participativos son, en múltiples ocasiones, instrumentales entre sí. Así, desde el punto de vista funcional, se puede hablar propiamente de una información que «acompaña» a las facultades de control y vigilancia, al procedimiento de consulta y, en fin, al procedimiento de negociación colectiva (Monereo, 1992: 114).

De esta forma, la información que se había definido como pasiva puede devenir activa en la medida en que va encaminada a verificar externamente el sentido de la decisión empresarial. En esta línea, puede afirmarse también que los representantes de los trabajadores en el marco de la negociación colectiva no tienen un derecho de información completamente pasivo, sino que disponen de una verdadera facultad de solicitar información - o derecho a solicitarla- sobre aquellos datos o asuntos que sean objetivamente, y de modo razonable, necesarios para negociar a favor de los trabajadores representados en la negociación. Desde este último punto de vista, como expresión típica de la obligación de negociar de buena fe, la dirección empresarial tiene el deber de presentar informaciones con motivo de la preparación técnica de las negociaciones colectivas y durante el transcurso de éstas. En este contexto negocial y prenegocial - en vista de la negociación-, el empresario tiene el deber de facilitar a los interlocutores colectivos de los trabajadores las informaciones que necesitan sobre los temas reconocidos como objeto de negociación. (...) A su vez, la consulta adquiere con frecuencia un papel instrumental respecto a la negociación colectiva, constituyéndose en la antesala que abre el procedimiento negocial propiamente dicho (Monereo, 1992: 118 y ss).

Conviene aclarar que este tipo de instrumentalidad interna entre diversas formas de participación en los casos concretos en los que existen consultas o negociaciones colectivas resulta obvia por la naturaleza de estos mecanismos y no admite negación alguna. Lo mismo ocurre en cuanto al control y vigilancia de la actividad empresarial, en la medida en que la información referida a ésta siempre servirá como instrumento para ejercer dicho control, sea cual sea el esquema de titularidad del propio derecho a estar informado. 
Nada tiene esto que ver con la instrumentalidad subjetiva tratada en los dos epígrafes anteriores, puesto que tanto si los derechos fueran otorgados a los trabajadores como si lo fueran a los representantes, tanto si los primeros actuaran de primera mano como si los derechos de estos fueran ejercidos por los representantes como mera correa de transmisión de los intereses obreros, la instrumentalidad interna existente entre las diferentes figuras mencionadas se mantendría inalterada. Así, lo que se ha tratado anteriormente es el régimen jurídico de un derecho informativo, consultivo o participativo jurídicamente protegido en cuanto facultad-interés de los representantes $-\mathrm{o}$ de los propios trabajadores - a ser informados por su empresario sobre la marcha empresarial, a ser consultados o a participar de primera mano (Fernández, 2006: 3215); mientras que en este epígrafe la instrumentalidad viene referida a ciertos momentos en los que un derecho de información o consulta es ejercido con un fin concreto de control, vigilancia, negociación, consulta, etc. Con todo, es obvia la interrelación entre las dos vertientes de instrumentalidad interna - entre los propios mecanismos de participación-, y externa —entre la finalidad del derecho concreto y su titular-.

\section{Bibliografía}

Baylos Grau, Antonio (coord.) (2013): Modelos de derecho del trabajo y cultura de los juristas, Albacete, Bomarzo.

Baylos Grau, Antonio (2009): Sindicalismo y Derecho Sindical, 4. ${ }^{a}$ edición, Albacete, Bomarzo.

Blasco Gascó, Francisco (2003), en AAVV: Derecho Civil. Parte general Derecho de la Persona, 4. ${ }^{\mathrm{a}}$ edición, Valencia, Tirant lo Blnach.

Fernández Docampo, Belén (2006): "Los derechos de información de los representantes legales de los trabajadores: carácter instrumental y contenido insuficiente», Aranzadi Social, n. ${ }^{\circ} 1$.

Garrido Pérez, Eva (1995): La información en la empresa. Análisis Jurídico de los Poderes de Información de los Representantes de los Trabajadores, Madrid, Consejo Económico y Social (CES).

Harnecker, Marta (1979): Clases Sociales y Lucha de Clases, Madrid, Akal.

Lenin, V. I. (1902): «¿Qué hacer?», en Obras escogidas, T. I., Moscú, Progreso.

Monereo Pérez, José Luis (1992). Los derechos de información de los representantes de los trabajadores, Madrid, Cívitas.

Poole, Michael (1995): Hacia una nueva democracia industrial, Madrid, Ministerio de Trabajo y Seguridad Social.

Rodríguez-Piñero, Miguel (1990): «Derechos de información del sindicato y paga de beneficios», Relaciones Laborales n. ${ }^{\circ} 2$. 